\title{
Analisis Brand equity Produk Fashion Hijab Merek Elzatta
}

\author{
Wiwik Widiyanti \\ Fakultas Ekonomi dan Bisnis Universitas Bina Sarana Informatika \\ e-mail: wiwik.www@bsi.ac.id

\begin{tabular}{ccc}
\hline Diterima & Direvisi & Disetujui \\
$06-01-2021$ & $28-01-2021$ & $29-01-2021$ \\
\hline
\end{tabular}

\begin{abstract}
Abstrak - Fashion Hijab Merek Elzatta termasuk dalam tiga besar dalam survei Top Brand Indonesia 2015-2020, sehingga merek ini cukup dikenal oleh masyarakat. Hal ini perlu dipertahankan dan ditingkatkan lagi mengingat hasil survei tersebut merek Elzatta selalu berada pada peringkat ketiga. Strategi pemasaran harus tepat sasaran dengan menggunakan salah satu alat bantu yaitu brand equity. Brand equity pada dasarnya menggambarkan nilai sebuah merek dari persepsi dan pengalaman konsumen terhadap brand tersebut. Penelitian ini bertujuan untuk menganalisis empat elemen brand equity yaitu brand awareness, brand association, brand loyality dan brand loyality sehingga diharapkan dapat menjadi sumbangan data untuk membuat strategi marketing pada merek tersebut. Hasil penelitian menunjukkan bahwa brand awareness merek Elzatta menempati posisi top of mind, sehingga merek ini selalu berada di benak para responden ketika membahas fashion hijab. Sementara tiga kesan brand association merek elzatta yaitu bahan kain yang berkualitas, model/desain yang bagus dan memberikan kenyamanan pada pemakainya merupakan asosiasi positif yang terbentuk. Brand loyality merek Elzatta menunjukkan bahwa atribut produk fashion hijab merek Elzatta sebagian besar sudah memperlihatkan kinerja yang tinggi. Hanya untuk atribut ketebalan bahan dan harga perlu diperbaiki dan ditingkatkan kinerjanya. Pada brand loyality merek Elzatta diperoleh data konsumen yang membeli karena harga lebih banyak dari konsumen yang membeli karena kebiasaan. Hal ini berpotensi konsumen akan berpindah merek apabila ada kenaikan harga. Adapun konsumen yang membeli karena satisfied adalah yang terbanyak, hal ini tentunya akan mempengaruhi loyalitas konsumen.
\end{abstract}

Kata Kunci: Brand equity, Brand awareness, Brand association, Brand loyality

\begin{abstract}
The Elzatta Hijab Fashion Brand is included in the top three in the 2015-2020 Top Brand Indonesia survey, so it is quite well known by the public. This needs to be improved and improved again considering the results of the survey Elzatta always rank third. The marketing strategy must be right on target using one of the tools, namely brand equity. Brand equity in the image illustrates the value of a brand from consumer perceptions and experiences of the brand. This study aims to analyze the four elements of brand equity, namely brand awareness, brand association, brand loyalty and brand loyalty which are expected to contribute data to create a marketing strategy for the brand. The results showed that brand awareness was in the top position of mind, so that these respondents were always in the minds of the respondents when discussing hijab fashion. While the three impressions of the Elzatta brand association, namely quality fabrics, good models / designs and providing comfort to the wearer, are positive associations that are formed. Elzatta's brand loyalty shows that the attributes of Elzatta's hijab fashion products have mostly achieved high performance. Only for the attributes of the thickness of the material and the price it is necessary to increase and improve its performance. On brand loyalty, Elzatta obtained data on consumers who buy because prices are more than consumers who buy out of habit. This is an accident that consumers will switch brands from rising prices. As for consumers who buy because satisfaction is the most, this of course will affect consumer loyalty.
\end{abstract}

Keywords: Brand equity, Brand awareness, Brand Partners, Brand Loyalty

\section{PENDAHULUAN}

Merek adalah nama, istilah, tanda, simbol, atau desain, atau kombinasi dari semuanya, yang dimaksudkan untuk mengidentifikasikan barang atau jasa dari satu penjual atau kelompok penjual dan mendiferensiasikan produk atau jasa dari para pesaing (Kotler \& Amstrong, 2012).
Merek menjadi salah satu alasan konsumen dalam mengambil keputusan pembelian suatu produk sehingga dapat dikatakan bahwa merek berpengaruh nyata dan kuat dalam pengambilan keputsan pembelian. Fashion Hijab Elzatta merupakan salah satu merek yang digemari masyarakat. Hal ini dapat dilihat dari antusiasisme masyarakat terhadap merek Elzatta. Fenomena ini disambut positif oleh pihak 
manajemen Elzatta dengan membuka 200 gerai di 100 kota besar di Indonesia pada tahun 2019, dan menargetkan menjadi 250 gerai di tahun 2020 (Birdieni, 2019).
Merek Elzatta tentunya mempunyai banyak pesaing yang juga digemari oleh masyarakat. Setidaknya ada tiga merek terkenal yang telah terjaring dalam survei Top Brand Indonesia seperti yang ada di table 1 berikut ini.

Tabel 1. Top Brand Indonesia Kategori Jilbab 2015 - 2020

\begin{tabular}{|l|l|l|l|l|l|l|}
\hline Merek & 2015 & 2016 & 2017 & 2018 & TBI 2019 & TBI 2020 \\
\hline Zoya & $28,9 \%$ & $44,8 \%$ & $39,4 \%$, & $24,9 \%$ & $27,2 \%$ & $27,4 \%$ \\
\hline Rabbani & $36,5 \%$ & $21,3 \%$ & $26,8 \%$ & $24,5 \%$ & $22,3 \%$ & $22,5 \%$ \\
\hline Elzatta & $8,4 \%$ & $12,6 \%$ & $13,0 \%$ & $19,8 \%$ & $15,5 \%$ & $19,3 \%$ \\
\hline
\end{tabular}

Sumber: (Top Brand Indonesia, 2020)

Berdasarkan table 1 dapat diperoleh kesimpulan bahwa pada hasil survei Top Brand Indonesia, merek Elzatta mengalami ketidak stabilan dari waktu ke waktu. Pada tahun 2015 - 2018 merek Elzatta mengalami kenaikan, akan tetapi pada tahun 2019 mengalami penurunan sebesar 4,3\%, sedangkan pada tahun 2020 mengalami kenaikan kembali sebesar $3,8 \%$. Hal ini membuktikan bahwa masyarakat semakin mengenal merek Elzatta dan bukan tidak mungkin jika strategi pemasaran merek Elzatta dikelola dengan tepat maka bisa menggeser zoya menjadi nomor satu top brand Indonesia.

Strategi pemasaran akan lebih mudah dibuat jika suatu produk sudah mempunyai brand equity yang positif. Brand equity ini nantinya yang akan membangun loyalitas pelanggan sehingga dapat menopang keberlangsungan hidup perusahaan.

Brand equity pada dasarnya menggambarkan nilai sebuah merek dari persepsi dan pengalaman konsumen terhadap brand tersebut. Perusahaan selalu membutuhkan Brand equity yang positif untuk setiap produknya agar mempermudah menarik pelanggan baru dan mempertahankan pelanggan setia dengan loyalitasnya (Handayani, 2020).

Bagi pelanggan, Brand equity yang positif dapat mempengaruhi rasa percaya diri dalam membelinya dan juga ada kepuasan tersendiri ketika memakainya. Selain itu Brand equity yang kuat juga sangat penting bagi perusahaan karena dapat memberikan efisiensi dan efektivitas pada program pemasaran, membentuk loyalitas yang tinggi pada pelanggan setia, menentukan harga yang tinggi sehingga laba perusahaan diharapkan juga semakin besar, memperluas lini produk, meningkatkan perdagangan dan memberikan keuntungan yang kompetitif (Durianto et al., 2017)

Menurut Durianto, ada empat kategori utama yang membentuk Brand equity yaitu brand awareness, brand association, brand loyality, dan brand loyality.

\section{Brand awareness}

Brand awareness adalah kemampuan seorang konsumen dalam mengenali dan mengingat suatu merek hanya dari melihat atau merasakan atribut merek tersebut, seperti nama merek, logo, warna, kemasan, dll (Uzair \& Singh, 2019)
Ada empat tingkatan brand awareness yaitu top of mind yang menggambarkan merek pertama kali diingat ketika seseorang ditanya mengenai suatu produk, brand recall mencerimankan merek-merek yang diingat setelah merek yang pertama kali disebut, brand recognition yaitu mengingat kembali suatu merek dengan bantuan penyebutan ciri-ciri atau atribut merek tersebut dan yang terakhir adalah brand unware dimana seseorang tidak mengenal merek yang ditanyakan(Maganti, 2020).

\section{Brand association}

Brand association merupakan kesan yang muncul diingatan seseorang atas suatu merek. Acuan dari brand association adalah atribut produk, atribut tak berwujud, manfaat bagi pelanggan,harga relative, penggunaan, pengguna/pelanggan, selebritas,gaya hidup, kelas produk, pesaing dan wilayah geografis (Thellefsen \& Sørensen, 2015).

\section{Brand loyality}

Brand loyality merupakan persepsi konsumen terhadap kualitas atau keunggulan suatu produk atau harapan atas jasa layanan yang diberikan (Alamsyah et al., 2021). Sementara dimensi dari brand loyality adalah kinerja, pelayanan, ketahanan, keandalan, karakteristik produk, kesesuaian dengan spesifikasi dan hasil (Durianto et al., 2017).

\section{Brand loyality}

Brand loyality merupakan suatu ukuran yang menggambarkan kemungkinan seorang pelanggan beralih ke merek produk lain, terutama jika merek tersebut mengalami perubahan baik harga maupun atribut lainnya (Yuliantari et al., 2020). Ada lima tingkatan brand loyality yaitu switcher, habitual buyer, satistfied buyer, likes the brand, comitted buyer. Tiap tingkatan tersebut mewakili tantangan pemasaran yang berbeda dan juga mewakili tipe asset yang berbeda dalam pengelolaan dan eksploitasinya (Durianto et al., 2017)

Brand equity digunakan sebagai alat bantu untuk menentukan strategi marketing yang akan dijalankan suatu perusahaan. Oleh karena itu diperlukan riset untuk mengumpulkan data dan 
menganalisanya. Seperti riset Brand equity pada produk pocari sweat di tiga universitas di Bogor dengan responden mahasiswa. Hasil dari riset tersebut menunjukkan bahwa pada produk minuman isotonic, pocari sweat menempati posisi top of mind pada brand awareness, sementara dalam brand association, memiliki dua citra merek yaitu aman untuk kesehatan dan berasa segar untuk menghilangkan dahaga. Adapun pada brand loyality digunakan analisis dengan biplot dan untuk brand loyality, pocari sweat belum memiliki loyalitas merek yang kuat (Pratama \& Munandar, 2016).

Lain halnya pada penelitian mengenai ekuitas pada sebuah coffe shop dengan merek Black Canyon, sebuah coffe shop franchise milik perusahaan Thailand yang sudah beroperasi di Indonesia. Hasil penelitian tersebut menunjukkan bahwa kesadaran merek konsumen dan non-konsumen Black Canyon berada pada tahap brand recognition. Asosiasi merek, persepsi kualitas, dan loyalitas merek konsumen Black Canyon baik. Loyalitas merek konsumen Black Canyon dalam penelitian ini telah mencapai tingkat tertinggi, yaitu comitted buyer. Asosiasi merek nonkonsumen Black Canyon dalam penelitian ini berada di tahap sedang (Octaviani et al., 2018)

Pada produk fashion hijab sendiri sudah ada penelitian dalam bentuk perbandingan ekuitas antara merek Zoya dengan Rabbani dimana diperoleh hasil penelitian tiga variabel terdapat dua dimensi yaitu brand awareness dan brand loyality yang menyatakan terdapat perbedaan pada produk jilbab antara merek Rabbani dengan merek Zoya dan satu dimensi menyatakan tidak terdapat perbedaan yaitu brand association (Jamilah et al., 2017).

Sementara itu penelitian mengenai pengukuran brand equity kerudung instan merek $\mathrm{X}$ di Bandung diperoleh hasil pengukuran menggunakan model brand equity mengungkapkan bahwa tingkat awareness kerudung instan merek $\mathrm{X}$ berada dalam kategori top of mind. Performansi kualitas yang terdapat pada atribut-atribut kerudung instan telah cukup baik, serta asosiasi yang terbentuk merupakan asosiasi yang memberi citra positif. Namun, tingkat loyalitas responden terhadap kerudung instan merek X sangat rendah (Qurniawan et al., 2018)

Penelitian atas merek elzatta sendiri pernah dilakukan, seperti penelitian mengenai pengaruh strategi diferensiasi dan harga terhadap keunggulan bersaing Elzatta Royal Plaza Surabaya dimana menghasilkan kesimpulan bahwa hasil uji $t$ menunjukkan bahwa strategi diferensiasi produk, kualitas layanan, dan harga memiliki pengaruh parsial terhadap keunggulan kompetitif. Sedangkan, strategi diferensiasi gambar dan strategi diferensiasi saluran distribusi tidak berpengaruh pada keunggulan kompetitif. Strategi diferensiasi produk adalah variabel yang paling dominan mempengaruhi keunggulan kompetitif (Firmansyah et al., 2019)

Penelitian lain atas merek Elzatta juga dilakukan di Pontianak dimana penelitian ini membahas mengenai pengaruh citra merek, harga, kualitas produk dan promosi terhadap keputusan pembelian jilbab Elzatta Hijab Store di Matahari Mall Pontianak. Hasil penelitian ini dapat disimpulkan bahwa variable citra merek, harga, kualitas produk, promosi berpengaruh positif dan signifikan terhadap keputuusan pembelian jilbab Elzatta Hijab Store di Matahari Mall Pontianak. Hal ini dapat diartikan citra merek, harga, kualitas produk dan promosi mampu mendorong responden untuk melakukan keputusan pembelian, dengan nilai signifikan sebesar 0,000 dan nilai $R^{2}$ sebesar $74 \%$ sedang sisanya sebesar $26 \%$ merupakan variable lain yang tidak diteliti di dalam penelitian tersebut (Kartika, 2017).

Adapun penelitian merek Elzatta mengenai brand equity belum pernah dilakukan. Hal ini tentunya menjadi novelty dari penelitian ini sehingga ada nilai kebaruan dari penelitian.

Berdasarkan pemaparan diatas maka penelitian mengenai brand equity produk fashion hijab merek Elzatta dilakukan dengan tujuan untuk mengetahui bagaimana analisis elemen-elemen dari brand equity yang meliputi brand awaresness, brand association, brand loyality dan brnad loyality pada produk fashion hijab merek Elzatta, sehingga nantinya dapat dipergunakan sebagai alat bantu untuk menentukan strategi pemasaran yang tepat untuk merek ini.

\section{METODE PENELITIAN}

Pengambilan sampel pada penelitian ini menggunakan teknik convenience sampling yaitu pengambilan sampel berdasarkan ketersediaan elemen dan kemudahan untuk mendapatkannya jadi siapa saja yang kebetulan ada atau dijumpai menurut keinginan peneliti bisa dijadikan sampel (Silalahi, 2015). Adapun jumlah responden yang diperoleh adalah sebesar 210 responden.

Data diperoleh dengan menyebarkan kuisioner secara online yang menggunakan skala likert dan essay sebagai suatu ukuran penilaian responden atas pertanyaan yang diajukan sehingga responden yang diperoleh berada di seluruh Indonesia. Pada pertanyaan dengan menggunakan skala likert terlebih dahulu diuji reliabilitas dan validitasnya sehingga data yang digunakan dapat reliabel dan valild.

Penelitian kuantitatif ini menggunakan metode analisis yang berbeda untuk setiap elemen brand equitynya. Adapun metode analisis tersebut adalah sebagai berikut.

\section{Brand awareness.}

Pengukuran yang terdiri dari empat sub variable yaitu top of mind, brand recall, brand recognition dan brand unaware ini dilakukan dengan membuat urutan dari jawaban pertanyaan yang terbesar. Oleh karena itu digunakan persentase untuk mengukurnya (Durianto et al., 2017).

2. Brand association. 
Pengukuran ini pada variable ini menggunakan uji Cohran dengan menggunakan data dengan skala pengukuran nominal atau informasi dalam bentuk terpisah dua (dikotomi), misalnya informasi "ya" atau "tidak" yang bertujuan mengetahui keberadaan hubungan antara beberapa variable. Ada beberapa tahap pengujian untuk mengeliminasi asosiasi yang tidak sesuai dengan kriteria sampai dengan mendapatkan hasil akhir yang benar-benar sesuai dengan kriteria (Durianto et al., 2017).

\section{Perceived quality}

Menurut Philip Kotler analisis arti penting-kinerja (importance-performance analysis) dapat digunakan untuk merangking berbagai elemen dari kumpulan jasa dan mengidentifikasi tindakan yang diperlukan. Dalam metode ini diperlukan pengukuran tingkat kesesuaian untuk mengetahui seberapa besar pelanggan merasa puas terhadap kinerja perusahaan, dan seberapa besar pihak penyedia jasa memahami apa yang diinginkan pelanggan terhadap jasa yang mereka berikan (Zeithaml et al., 1990).

4. Brand loyality

Variabel ini memiliki lima sub variable (switcher, habitual buyer, satisfied buyer, Likes the brand, dan comitted buyer) yang menggunakan pengukuran yang sama yaitu berdasarkan persentase terhadap jawaban yang mengarah pada satu jawaban pertanyaan dengan skala likert.

\section{HASIL DAN PEMBAHASAN}

\section{A. Gambaran Karakteristik Responden}

Data hasil penyebaran kuisioner melalui online dengan metode convenience sampling telah diperoleh sebanyak 210 responden yang tersebar di seluruh Indonesia yang terdiri dari 9\% laki-laki dan $91 \%$ wanita.

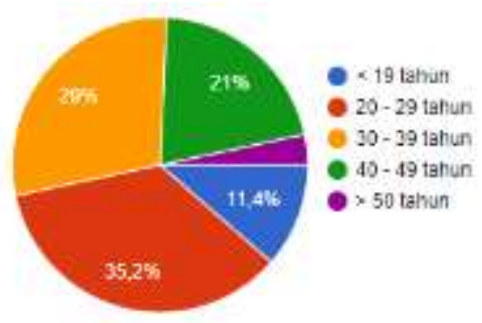

Sumber: Data yang diolah, 2020

Gambar 1 Karakteristik responden menurut usia
Adapun karakteristik responden berdasarkan usia, yang terbanyak adalah pada usia 20-29 tahun sebesar 35,2\% disusul usia 30-29 tahun sebesar $29 \%$ menempati posisi kedua. Pada posisi ketiga, keempat dan kelima adalah responden dengan usia 20-29 tahun sebesar $21 \%$, usia kurang dari 19 tahun sebesar $11,4 \%$ dan lebih dari 50 tahun sebesar $3,4 \%$.

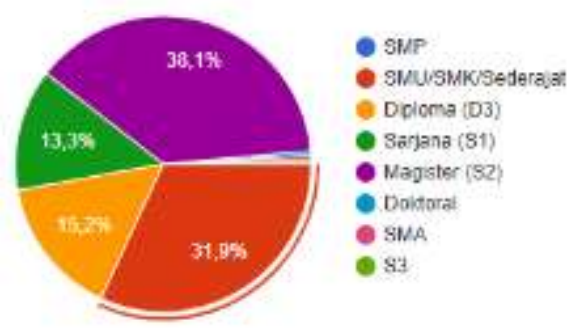

Sumber: Data yang diolah, 2020

Gambar 2. Karakteristik responden berdasarkan pendidikan terakhir

Pada gambar 3 terlihat bahwa pendidikan terakhir responden yang terbanyak adalah magister sebanyak $38,1 \%$ dan posisi yang paling sedikit adalah Doktoral sebanyak $0,5 \%$. Hal ini menunjukkan pendidikan terakhir dari responden menyebar dari SMU/SMK/Sederajat sampai dengan Doktoral.

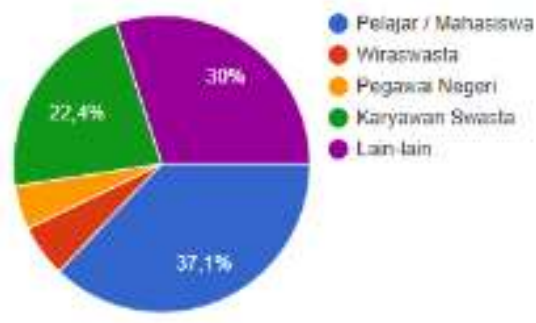

Sumber: Data yang diolah, 2020

Gambar 3. Karakteristik responden menurut pekerjaan

Sementara itu, karakteristik responden berdasarkan pekerjaan terlihat dari gambar 3, responden terbanyak adalah pelajar/mahasiswa sebesar $37 \%$ dan yang terkecil sebesar $4,8 \%$ mempunyai pekerjaan sebagai PNS.

\section{B. Hasil Penelitian}

1. Uji Reliabilitas dan Validitas..

Langkah awal penelitian adalah melakukan uji reliabilitas dan, dimana jika nilai Cronbach alpha > 0,6 maka data penelitian dikatakan reliabel. Berikut ini adalah hasil uji reliabilitas penelitian. 
Tabel 2. Hasil Uji Reliabilitas

\begin{tabular}{|c|c|c|c|}
\hline Variabel & Cronbach Alpha & $\begin{array}{c}\text { Dasar } \\
\text { keputusan }\end{array}$ & Keterangan \\
\hline $\begin{array}{c}\text { Brand } \\
\text { association }\end{array}$ & 0,663 & 0,6 & Reliabel \\
\hline Brand loyality & 0,849 & 0,6 & Reliabel \\
\hline Brand loyality & 0,623 & 0,6 & Reliabel \\
\hline
\end{tabular}

Sumber: Data yang sudah diolah, 2020

Berdasarkan table 2 terlihat bahwa ketiga variable mempunyai nilai Cronbach alpha diatas 0,6 sehingga dapat disimpulkan bahwa data yang diperoleh adalah reliabel. Ada satu variable yaitu brand awareness yang tidak dapat diuji reliabilitasnya karena data tersebut berisi jawaban singkat yang tidak bias diukur menggunakan skala. Adapun pada uji validitas dari semua data dalam penelitian ini diperoleh hasil valid karena hasil nilai sinifikansi kurang dari 0,05 .

\section{Brand awareness}

Variabel ini memberikan informasi mengenai tingkat kemampuan responden dalam mengenal dan mengingat fashion hijab merek elzatta. Ada empat sub variable yaitu top of mind, brand recall, brand recognition dan brand unaware. Cara pengukuran pada empat sub variable ini adalah dengan melihat besarnya persentase yang diperoleh setelah dilakukan olah data.

Adapun data yang diperoleh dari responden mengenai produk fashion hijab di Indonesia pada ketiga sub variable dalam brand awareness dapat dilihat pada table 3, 4, dan table 5 dibawah ini.

Table3. Top of mind Produk Fashion Hijab di Indonesia

\begin{tabular}{|l|c|}
\hline Merek Fashion Hijab & $(\%)$ \\
\hline Elzatta & 40 \\
Rabbani & 25 \\
Zoya & 22 \\
Lain-lain & 13 \\
\hline Total & 100 \\
\hline
\end{tabular}

Sumber: Data yang diolah, 2020

Table 3 menjelaskan jawaban spontan dari responden ketika diberikan pertanyaan merek produk fashion hijab apa yang pertama kali diingat. Teryata merek Elzatta mempunyai persentase terbesar yaitu 40\% sehingga dapat disimpulkan bahwa merek Elzatta menjadi top of mind responden.
Table 4. Brand recall Produk Fashion Hijab di Indonesia

\begin{tabular}{|l|l|}
\hline Merek Fashion & $(\%)$ \\
Hijab & \\
\hline Elzatta & 38 \\
Zoya & 29 \\
Rabbani & 18 \\
Lain-lain & 15 \\
\hline Total & 100 \\
\hline
\end{tabular}

Sumber: Data yang diolah, 2020

Table 4 menjelaskan jawaban dari responden ketika diberikan pertanyaan merek produk fashion hijab apa yang mereka ketahui. Tiga merek yang paling banyak disebut yaitu Elzatta, Zoya dan Rabbani. Di sini Elzatta masih menduduki posisi teratas pada brand recall yaitu sebesar $38 \%$.

Tabel 5. Brand recognition dan Brand unaware Merek Elzatta

\begin{tabular}{|l|l|c|}
\hline No & Jawaban & $\%$ \\
\hline 1 & $\begin{array}{l}\text { Ya, saya mengenal dan telah } \\
\text { menuliskannya dalam pertanyaan } \\
\text { sebelumnya }\end{array}$ & 70 \\
\hline 2 & $\begin{array}{l}\text { Ya, saya mengenal setelah mengisi } \\
\text { kuisioner ini }\end{array}$ & 21 \\
\hline 3 & Tidak mengenal sama sekali & 9 \\
\hline
\end{tabular}

Tabel 5 menjelaskan jawaban responden atas pertanyaan apakah mengenal produk fashion hijab merek Elzatta. Hal ini dilakukan untuk mengetahui seberapa banyak responden yang perlu diingatkan akan keberadaan merek Elzatta. Jawaban nomor satu adalah termasuk dalam kelompok top of mind dan brand recall, sedang jawaban nomor dua termasuk dalam kelompok brand recognition yaitu responden telah mengingat merek Elzatta ketika diberikan bantuan dengan pertanyaan yang menyebutkan merek tersebut. Sedangkan jawaban nomor tiga termasuk dalam brand unaware sebesar $9 \%$

Dari data yang diperoleh pada table 3, 4, dan 5 tersebut maka dapat disimpullkan bahwa merek Elzatta memang menjadi top of mind pada benak responden, akan tetapi besarnya persentase tidak begitu jauh dengan posisi kedua top of mind yaitu 
merek rabbani sebesar 25\%,, artinya hanya selisih $15 \%$ saja. Hal ini secara tidak langsung menimbulkan ancaman bagi merek Elzatta dan sebaiknya manajemen merek Elzatta bekerja lebih keras lagi dalam membranding mereknya agar semakin dikenal oleh masyarakat.

Hasil penelitian mengenai top of mind pada brand awareness ini sejalan dengan hasil penelitian pada kerudung instan merek $X$ di Bandung namun dengan perolehan persentase top of mind yang berbeda yaitu sebesar $80 \%$. Persentase yang sangat besar, sehingga dapat diartikan bahwa kerudung instan merek X selalu ada di benak responden di Bandung (Qurniawan et al., 2018). Perbedaan ini kemungkinan dikarenakan perbedaan jenis produk dan pengetahuan responden.

\section{Brand association}

Variabel ini adalah menjelaskan penilaian responden terkait fashion hijab merek elzatta. Penilaian ini diambil dari responden yang telah mengenal dan membeli fashion hijab merek Elzatta yaitu sebanyak 191 responden. Ada enam kesan yang dapat dilihat pada table 6 berikut ini.

\section{Tabel 6. Brand association Merek Elzatta}

\begin{tabular}{|l|l|c|}
\hline $\begin{array}{l}\text { No } \\
.\end{array}$ & Asosiasi & $\begin{array}{c}\text { Menjawab } \\
\text { Ya ( \% ) }\end{array}$ \\
\hline 1 & Berkesan Eksklusif & 85 \\
\hline 2 & Bahan kain yang berkualitas & 91 \\
\hline 3 & Model /Desain bagus & 89 \\
\hline 4 & Harga murah & 46 \\
\hline 5 & Memberikan kenyamanan & 92 \\
\hline 6 & Banyak jenis dan ukuran & 85 \\
\hline
\end{tabular}

Sumber: Data yang diolah 2020

Dari enam asosiasi pada tabel 5, akan dilakukan uji Cochran secara bertahap mulai dari 6 asosiasi, 5 asosiasi, 4 asosiasi, dan seterusnya sesuai dengan jumlah jawaban "Ya" dari setiap asosiasi sampai pengujian asosiasi menunjukkan adanya hubungan yang signifikan antara asosiasi yang dipilih responden.

Adapun hipotesis yang digunakan pada brand association adalah sebagai berikut:

Ho = Kemungkinan jawaban "Ya" adalah sama untuk semua asosiasi

H1 = Kemungkinan jawaban "Ya" adalah berbeda untuk semua asosiasi

Sementara itu dasar pengambilan keputusannya adalah:

$\mathrm{Q}>\mathrm{X}_{\text {tabel }}^{2}$ maka Ho ditolak

$\mathrm{Q}<\mathrm{X}^{2}$ tabel maka Ho diterima.

Atau dengan menggunakan Asymp Sig sebagai berikut:

Asymp. Sig $<$ taraf nyata $(\boldsymbol{\alpha}=0,05)$ maka Ho ditolak Asymp. Sig $>$ taraf nyata $(\boldsymbol{\alpha}=0,05)$ maka Ho diterima Hasil dari pengujian Cochran terhadap seluruh asosiasi dirangkum dalam tabel 7 .

Tabel 7 Rangkuman Pengujian Asosiasi Merek

\begin{tabular}{|c|l|r|r|r|r|l|}
\hline Pengujian ke & $\begin{array}{c}\text { Asosiasi yang } \\
\text { diuji }\end{array}$ & Q hitung & $\mathrm{X}^{2}$ tabel & Asymp Sig & Alpha & Keterangan \\
\hline 1 & $1,2,3,4,5,6$ & 261,293 & 11,0705 & 0,00 & 0,05 & Ho ditolak \\
\hline 2 & $1,2,3,5,6$ & 13,940 & 9,4877 & 0,00 & 0,05 & Ho ditolak \\
\hline 3 & $2,3,5,6$ & 10,459 & 17,815 & 0,00 & 0,05 & Ho ditolak \\
\hline 4 & $\mathbf{2 , 3 , 5}$ & $\mathbf{3 , 3 7 9}$ & $\mathbf{5 , 9 9 1}$ & $\mathbf{0 , 4 9 7}$ & $\mathbf{0 , 0 5}$ & Ho diterima \\
\hline
\end{tabular}

Sumber: Data yang diolah 2020

Pengujian ke-4 dilakukan dengan melibatkan 3 asosiasi, yaitu butir asosiasi kedua, ketiga, dan kelima sehingga dari pengujian tersebut diperoleh asosiasiasosiasi yang membentuk brand image fashion hijab merek Elzatta. Dari data pada table 7 maka dapat disimpulkan bahwa asosiasi yang terbentuk dari merek Elzatta ini adalah merek fashion hijab dengan bahan kain berkualitas dimana model/desain yang dibuat dangat bagus dan memberikan kenyamanan pada pemakainya. Asosiasi yang terbentuk tersebut adalah termasuk asosiasi yang baik dan positif, sehingga dapat memberi keyakinan pada masyarakat untuk membeli fashion hijab merek Elzatta.
Hasil penelitian mengenai brand association ini sejalan dengan hasil penelitian pada kerudung instan merek X di Bandung dengan asosiasi yang terbentuk dari data yang telah diolah adalah kerudung instan yang memiliki banyak varian warna dan merupakan merek yang terkenal, serta penggunaannya yang lebih praktis (Qurniawan et al., 2018). Perbedaan ini tentunya dikarenakan masing-masing produk mempunyai keunggulan masing-masing.

4. Brand loyality

Variabel ini adalah menjelaskan mengenai persepsi kualitas dari responden atas produk fashion hijab merek Elzatta. Pengukuran brand loyality dilakukan dengan cara membandingkan tingkat kepentingan dan tingkat kinerja. Tingkat kepentingan 
(importance) merupakan gambaran dari tingkat kepentingan atas keberadaan suatu atribut atas produk fashion hijab merek Elzatta Sedangkan tingkat kinerja (performance) adalah gambaran dari penilaian konsumen terhadap atribut kualitas dari produk fashion hijab merek Elzatta. Perbandingan antara tingkat kepentingan (importance) dan tingkat kinerja (performance) akan dipetakan dalam scharter diagram, yang terbagi atas empat kuadran. Sumbu vertikal (tegak) merupakan importance, sementara sumbu horisontal (mendatar) merupakan performance.

Dalam analisis brand loyality dari merk dilakukan terhadap responden yang pernah merasakan atau pernah menggunakan produk fashion hijab merek Ezatta yaitu sebanyak 191 responden.

Tabel 8. Nilai Rata-rata Atribut pada Tingkat Importance dan Performance Merek Elzatta

\begin{tabular}{|l|l|c|c|}
\hline No & \multicolumn{1}{|c|}{ Atribut } & Importance & Performance \\
\hline 1 & Harga & 7,82 & 6,43 \\
2 & Tingkat Kenyamanan pemakaian & 7,56 & 9,53 \\
3 & Model yang selalu kekinian & 7,83 & 9,82 \\
4 & Tingkat kehalusan bahan & 7,48 & 9,44 \\
5 & Tingkat ketebalan bahan & 7,23 & 7,10 \\
\hline
\end{tabular}

Sumber: Hasil Pengolahan Data (2020)

Nilai rata-rata yang ada pada table 8 terbentuk empat kuadran seperti terlihat pada gambar 1 berikut ini selanjutnya dibuat schatter diagram yang didalamnya

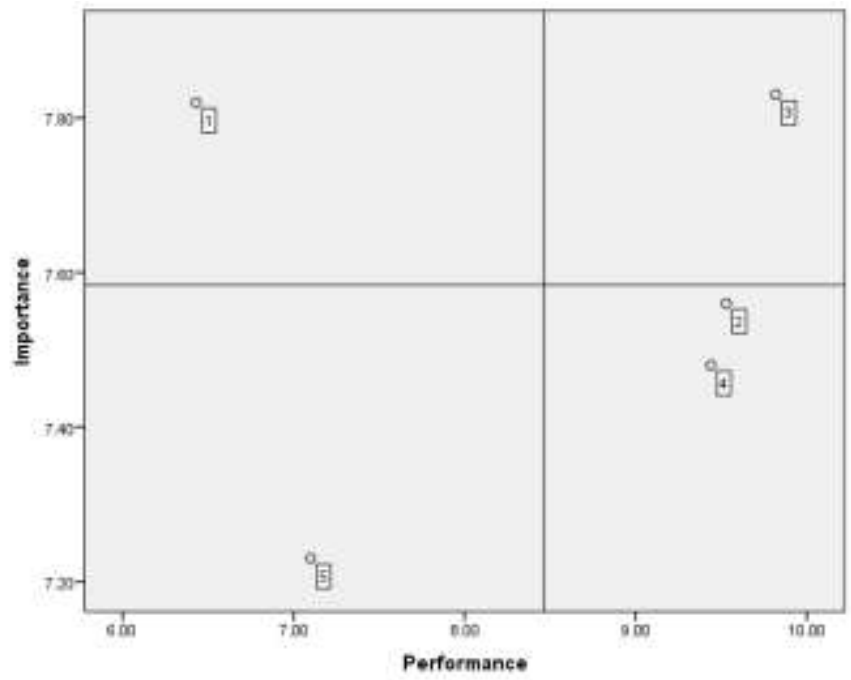

Sumber: Data yang diolah, 2020

Gambar 4. Schatter Diagram Brand loyality

Berdasarkan gambar 4 diatas diperoleh data bahwa kelima atribut tersebar di empat kuadran. Empat kuadran tersebut adalah:

1. Kuadran 1 yang mencerminkan bahwa tingkat kinerja (performance) lebih rendah dibandingkan dengan tingkat kepentingan konsumen terhadap atribut tersebut. Dari hasil perhitungan dan pemetaan, atribut yang masuk dalam kuadran ini adalah atribut ke-1 (harga). Atribut ini harus menjadi prioritas utama bagi fashion Hijab merek Elzatta untuk ditingkatkan kinerjanya.

2. Kuadran 2 yang mencerminkan bahwa tingkat kinerja dan tingkat kepentingan konsumen dari fashion hijab merek Elzatta sudah sesuai. Atribut yang masuk dalam kuadran ini adalah atribut ketiga (model yang selalu kekinian). Atribut tersebut sudah baik di mata konsumen, jadi harus dipertahankan tingkat kinerjanya.

3. Kuadran 3 yang mencerminkan bahwa tingkat kinerja atribut fashion hijab merek Elzatta adalah rendah dan tingkat kepentingan dari atribut merk juga rendah. Atribut yang masuk dalam kuadran ini adalah atribut kelima (ketebalan bahan). Atribut tersebut menjadi prioritas untuk ditingkatkan kinerjanya karena kepentingan atribut bagi konsumen juga rendah

4. Kuadran 4 yang mencerminkan bahwa tingkat kinerja atribut fashion hijab merek Elzatta adalah tinggi, sedangkan tingkat kepentingannya rendah bagi konsumen. Atribut-atribut yang masuk dalam kuadran ini adalah atribut kedua (tingkat kenyamanan pemakainan) dan keempat (tingkat kehalusan bahan) 
Hasil penelitian ini sejalan dengan penelitian pada coffe shop Black Canyon yang sama-sama membahas brand loyality tapi dengan menggunakan pengukuran berdasarkan mean dan standar deviasi dimana dihasilkan atribut reliability memiliki nilai mean tertinggi sehingga menunjukkan bahwa karyawan mampu memberikan pelayanan yang dapat diandalkan dan akurat oleh konsumen (Octaviani et al., 2018).

\section{Brand loyality}

Variabel ini menjelaskan seberapa kuat brand produk fashion Elzatta sehingga para pelanggan mau mengulang kembali pembelian. Pada variable ini ada lima tingkatan brand loyality yaitu switcher, habitual buyer, satisfied buyer, liking the product dan comitted buyer yang hasilnya dapat diilihat pada gambar piramida berikut ini:

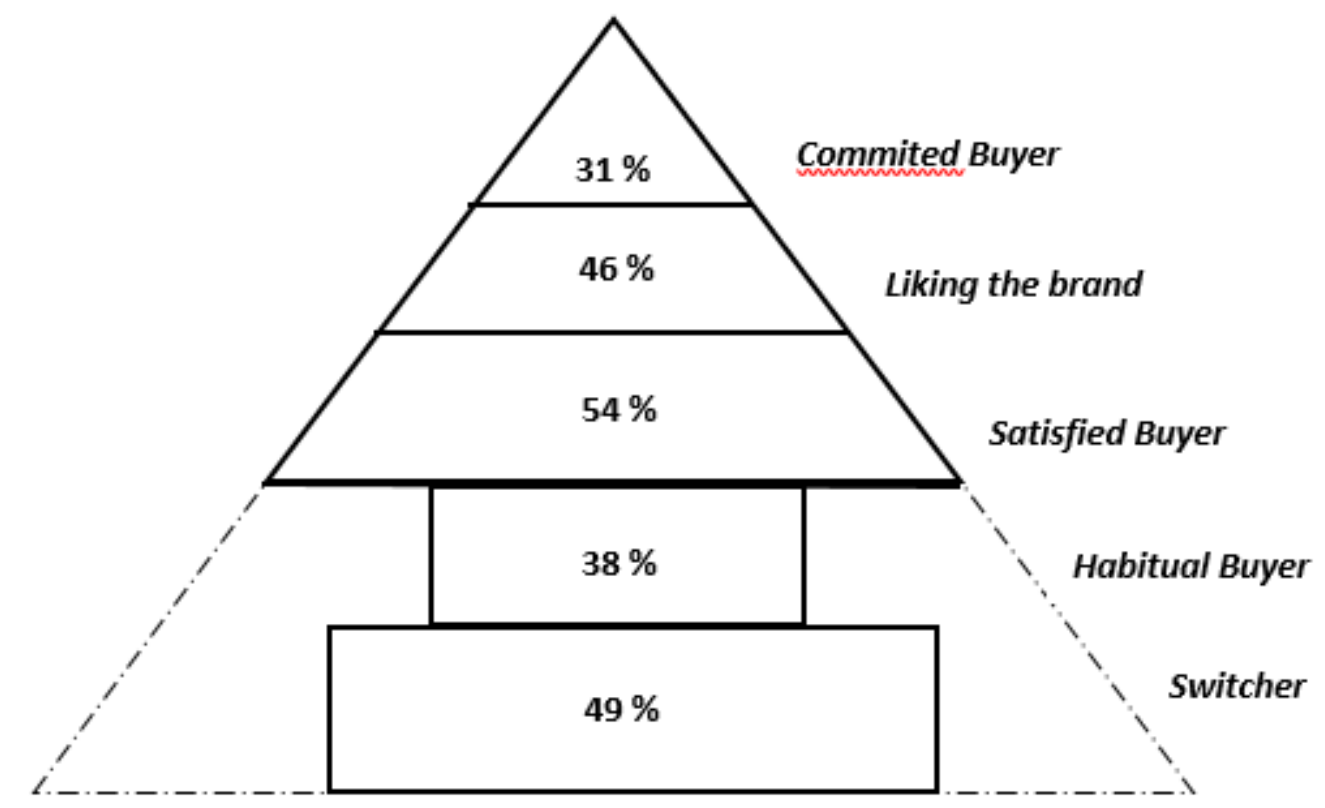

Sumber: Data yang diolah, 2020

Gambar 5. Piramida Brand loyality Produk Fashion Merek Elzatta

Hasil ideal dari brand loyality adalah berbentuk piramida dimana semakin keatas, semakin mengecil. Pada gambar piramida brand loyality produk fashion merek Elzatta di atas menjelaskan bahwa kelima tingkatan brand loyality terlihat semakin mengecil keatas. Persentase responden yang termasuk dalam tingkatan switcher adalah sebesar $49 \%$ yang artinya bahwa responden yang mempunyai sensitifitas terhadap harga mendekati separuh dari responden. Hali ini sedikit membahayakan bagi merek Elzatta karena jika terjadi perubahan harga, maka ada potensi perpindahan pembelian ke merek selain Elzatta. Namun pada habitual buyer diperoleh persentase sebesar $38 \%$, sehingga dapat diartikan alasan responden membeli merek ELzatta berdasarkan kebiasaan. Adapun persentase satisfied buyer menempati posisi persentase terbesar diantara kelima indicator brand loyality yaitu sebesar $54 \%$. Hal ini dapat diartikan responden lebih dari separuh responden puas dengan produk fashion hijab merek Elzatta. Sejalan dengan itu, likes the brand juga mempunyai porsi mendekati $50 \%$ yang artinya sebesar $46 \%$ dari responden sangat menyukai merek Elzatta. Pada puncak indicator loyaity adalah comitted buyer dimana diperoleh sebesar $31 \%$. Hal ini dapat diartikan bahwa responden yang mau merekomedasikan produk fashion hijab merek Elzatta sebesar $31 \%$, sehingga manajemen perlu membuat strategi pemasaran untuk meningkatkan comitted buyer ini.

\section{KESIMPULAN}

Mengacu pada tujuan penelitian yaitu menganalisis empat elemen brand equity yaitu brand awareness, brans associate, brand loyality dan brand loyalty maka dapat disimpulkan bahwa brand awareness merupakan kesadaran seseorang atas merek. Hal ini penting diketahui oleh tim marketing sebagai dasar dari pengaturan strategi marketing. Mengacu pada hasil penelitian brand awareness diatas, merek Elzatta menempati posisi top of mind di benak $40 \%$ responden. Artinya ketika responden diminta menyebutkan merek produk fashion hijab maka yang tercetus pertama kali adalah merek Elzatta. Hal ini tentunya menjadi keuntungan bagi marketing merek Elzatta karena akan berpengaruh pada loyalitas pelanggan atas merek tersebut. Pelanggan terbiasa dan sering memilih sesuatu yang mereka kenal. Keuntungan lainnya bagi merek 
Elzatta dengan menjadi top of mind produk fashion hijab adalah dapat mengurangi biaya iklan dan promosi. Walaupun menempati posisi top of mind, ada $9 \%$ dari responden yang tidak mengenal merek Elzatta (brand unaware). Hal ini tentunya harus mendapat perhatian agar merek Elzatta dikenal oleh semua orang di Indonesia.

Brand association merupakan segala kesan yang muncul di benak seseorang. Kesan-kesan tersebut muncul dari pengalaman konsumen setelah menggunakan produk dengan merek tersebut. Semakin sering konsumen berinteraksi dengan merek tersebut, semakin banyak asosiasi itu muncul. Hasil penelitian brand association menyatakan bahwa ada tiga asosiasi pada merek elzatta yaitu bahan kain yang berkualitas, model/desain yang bagus dan memberikan kenyamanan pada pemakainya. Ketiga asosiasi ini membentuk brand image merek Elzatta.

Brand image yang sudah terbentuk memberikan beberapa manfaat bagi manajemen Elzatta, diantaranya adalah selain sebagai ciri pembeda dari merek lain juga dapat digunakan sebagai daya tarik konsumen sehingga lebih mudah mendapatkan konsumen baru dan mendapatkan loyalitas dari konsumen lama. Tidak hanya itu, merek Elzatta bisa menetapkan harga yang lebih tinggi dan juga dapat melakukan diferensiasi produk.

Brand loyality merupakan persepsi pelanggan terhadap keseluruhan kualitas atau keunggulan suatu produk. Hal ini perlu dikelola dan dipahami untuk kepentingan perusahaan. Hasil penelitian brand loyality menunjukkan bahwa atribut produk fashion hijab merek Elzatta sebagian besar sudah memperlihatkan kinerja yang tinggi. Hanya untuk atribut ketebalan bahan dan harga perlu diperbaiki dan ditingkatkan kinerjanya.

Brand loyality merupakan elemen yang sangat penting bagi perusahaan. Elemen ini menentukan kelangsungan hidup perusahaan. Pada hasil penelitian diperoleh data konsumen membeli karena harga lebih banyak dari konsumen yang membeli karena kebiasaan. Hal ini berpotensi konsumen akan berpindah merek apabila ada kenaikan harga. Adapun konsumen yang membeli karena satisfied adalah yang terbanyak, hal ini tentunya akan mempengaruhi loyalitas konsumen.

\section{REFERENSI}

Alamsyah, D. P., Othman, N. A., Bakri, M. H., Udjaja, Y., \& Aryanto, R. (2021). Green awareness through environmental knowledge and brand loyality. Management Science Letters Journal, 11(1), 271-280. https://doi.org/10.5267/j.msl.2020.8.006

Birdieni, B. (2019). Targetkan 250 Gerai, Elzatta Kembangkan Joint Investment. Gatra. https://www.gatra.com/detail/news/453589/ek onomi/targetkan-250-gerai-elzatta-

kembangkan-joint-investment

Durianto, D., Sugiarto, \& Sitinjak, T. (2017). Strategi Menaklukkan Pasar Melalui Riset Ekuitas dan Perilaku Merek. PT Gramedia Pustaka Utama.

Firmansyah, M. A., Mahardhika, B. W., \& Susanti, A. (2019). Pengaruh Strategi Diferensiasi Dan Hargaterhadap Keunggulan Bersaing Elzatta Royal Plaza Surabaya. Jurnal Balance, 2. http://journal.umsurabaya.ac.id/index.php/balance/article/view/ 3138

Handayani, M. T. (2020). Pentingnya brand equity dan cara efektif membangunnya. Ekrut Media. https://www.ekrut.com/media/brand-equityadalah

Jamilah, N. N., Rapini, T., \& Sumarsono, H. (2017). Analisi Perbandingan Brand equity Produk Jilbab Antara Merek Rabbani Dengan Merek Zoya pada Mahasiswi Fakultas Ekonomi di Universitas Muhammadiyah Ponorogo. Jurnal Ekonomi, Manajemen Dan Akuntansi, 1 No 1.

Kartika, C. (2017). Pengaruh Citra Merek, Harga, Kualitas Produk dan Promosi Terhadap Keputusan Pembelian Jilbab Elzatta Hijab Stoe di Matahari Mall Pontianak. Jurnal Manajemen Update, $\quad 6 \quad$ no 4 . https://jurnal.untan.ac.id/index.php/ejmfe/artic le/view/23354

Kotler, P., \& Amstrong, G. (2012). Prinsip-Prinsip Pemasaran. Erlangga.

Maganti, S. (2020). Brand awareness : A Case Study on TV Advertisements Brand awareness: A Case Study on TV Advertisements. Mukt Shabd Journal, April.

Octaviani, C., Iskandar, S., \& Jokom, R. (2018). Analisa Deskripsi Ekuitas Merek Black Canyon Surabaya. Jurnal Hospitality Dan Manajemen Jasa, 6 no 2. http://publication.petra.ac.id/index.php/manaje men-perhotelan/article/view/7476

Pratama, F., \& Munandar, J. M. (2016). Analisis Brand equity Pocari Sweat Dalam Persaingan Industri Minuman (Studi Kasus: Mahasiswa di Bogor). Jurnal Manajemen Dan Organisasi, 1(1), https://doi.org/10.29244/jmo.v1i1.14147

Qurniawan, M., Kusmaningrum, \& Arijanto, S. (2018). Pengukuran Brand equity Kerudung. Jurnal Online Institut Teknologi Nasional, 2(1), 378-388.

Silalahi, U. (2015). Metode Penelitian Sosial Kuantitatif. Bandung. Refika Aditama.

Thellefsen, T., \& Sørensen, B. (2015). What brand associations are. Sign Systems Studies Journal, 43(2-3),

191-206. 
https://doi.org/10.12697/SSS.2015.43.2-3.03

Top Brand Indonesia. (2020). Tob Brand Indonesia. https://www.topbrandaward.com/en/2019/07/kerudung-bermerekfase-2-2019/

Uzair, M., \& Singh, R. (2019). Brand awareness and Marketing Campaign for Nilkamal. International Journal of Trend in Scientific Research and Development, Volume-3(Issue-
3), https://doi.org/10.31142/ijtsrd23120

$877-882$

Yuliantari, K., Nurhidayati, \& Sugiyah. (2020). Brand Loyalty Perawatan Wajah ( Skin Care) Wardah Gentle Face Wash. 8(2), 1-6.

Zeithaml, V. A., Parasuraman, A., \& Berry, L. . (1990). Delivering Quality Service. The Free Press. 